JUAN ALCÁNTARA

\title{
[CALCETINES]
}

- hoy sali a la noche

frío en las extremidades

no veía nada pero

mojados los

me mojaba

calcetines, unas

- hoy salí a la noche

gotitas de agua sentía

$$
\text { iy las }
$$

no veía nada pero

en los lentes

me mojaba

aunque no veía

- hoy salí a la noche

mojados los

no veía nada pero

calcetines, unas

me mojaba

gotitas de agua sentía

$$
\text { estrellas? }
$$

- hoy salí a la noche

en los lentes

no veía nada pero

aunque no veía

me mojaba

frío en las extremidades

- hoy sali a la noche

calcetines, unas

no veía nada pero

$$
\text { ¿y las estrellas? }
$$

gotitas de agua sentía 
me mojaba

en los lentes

- hoy salí a la noche

aunque no veía

no veía nada pero

frío en las extremidades

me mojaba

mojados los

$$
\text { [...] }
$$

\section{PoEMA ENCONTRADO EN UN LIBRO \\ DE AleXIS DE TOCQUEVILLE}

en los desiertos

más remotos

[del mundo]

los indios

saludan

[a los caminantes]

diciendo

bonjour 